\title{
The Psychological Approach to Patients as seen by a Physiotherapist
}

\author{
by INGEBORG SCHROEDL
}

\author{
Senior Physiotherapist, Tara Hospital, Johannesburg. State Licenced Rostock, Germany
}

In this era in which we live, now universally regarded as the "era of anxiety", there is a greater and growing awareness of the role that practical psychology or generally speaking, mental hygiene plays. We have many examples of this, such as the bringing up of children which is so vastly different from the Victorian era. There are child-guidance clinics and countless numbers of books on this subject. We have marriage guidance counsellors; social clubs have been formed to care for the psychological needs of the aged. There are many more examples, for instance the expansion of the field of psychosomatic medicine, etc. We as a professional group cannot isolate ourselves from this growing recognition and have to come to terms with it individually is well as in our role as therapists.

The psychological approach to patients, or any human being for that matter, is a dynamic living situation which has so many facets that one cannot hope to cover this vast subject beyond the scope of this contribution.

What do we mean by "psychological approach to patients"? My own personal definition would be that it is "an approach that has an awareness and an understanding of the human inter-relationship between therapist and patient", thus not only recognizing the emotional and psychological needs of the patient but also of the therapistand to use this therapeutically.

We as physiotherapists all have one thing in common and that is, we are all treating patients in our professional capacity.

Our technical methods of applying our various treatments may vary slightly, but not greatly. Our approach to patients varies very much. It is important to realize that every patient is a unique human being and an individual who presents a new challenge to us and is striving for his adjustment.

There may be a certain type of patient such as the predominantly anxious patient, the predominantly aggressive or demanding patient (though we should beware of labelling), all of them within normal limits or otherwise. But the degree of aggression or anxiety will never be identical nor the manner in which it is exhibited.

In the same way we as therapists differ. We are also human beings and as such unique and have our emotional problems and shortcomings. The sooner we realize our own needs, the patient's needs, and the patterns of satisfying those needs, the more profitable can we make this human relationship and our approach to the patient-even to the benefit of physiotherapy.

The first important step is therefore to have a greater understanding and acceptance of ourselves as persons-of the patient as a person and not just another case, and understanding of the inter-reaction of the two personalities.

There are enough people also in our profession who do not even want to know about the psychological needs of the patient. Most of us do readily accept these needs, but we have difficulty in understanding or accepting them, because they might frustrate our own needs completely. We are so often blissfully unaware of the processes that go on within us or we ignore them, because this might be a painful experience.

So we cover up under the cloak of a superior being in our white uniform which gives us already a sense of security and use the patient indiscriminately to satisfy our own ego.

I would like to make one point quite clear, I am pleading for greater understanding of the patient and ourselves and I do not by any means visualize a process by which we feel impelled to psychoanalyze every move we or the patient make and to make our own interpretations. We are not psychologists nor psychiatrists but physiotherapists and a little knowledge can be very dangerous. We need a degree of insight, an ability to observe the patient objectively and to come to terms with our own problems so that we can accept the patient in a non-judgemental way.

How can we achieve this? One learns by experience. We have all had a certain amount of experience in human relations-starting from the mother-child relationship, which is the basis of the first group; our whole life is made up of movements from one group to the other; school, home, university and in our work. We thus evolve our own pattern of behaviour which we use with a varying degree of success. We have all experienced anxiety, aggression, guilt, frustration, resentment, etc. How we deal with it and work out our adjustment-techniques is up to us. We may have been guided by other people, but we still have to solve the problems ourselves. Our so-called normal patient goes through very much the same experience and we should therefore not find it too difficult to understand him. We must realize that one cannot lay down any hard and fast rules (such as: this is the way to deal with a demanding, aggressive patient). It will never be successful, because it is a living situation where one cannot anticipate every mood and move of our patient and the therapist.

You have all encountered this phenomenon. For example: You treat a very demanding patient, a really trying patientthe type who is never comfortable nor satisfied, the so-called "pain in the neck". You might have been able to contain your frustration for weeks on end and think that you have managed to cope with him. Then one fine morning, when you missed the bus because you overslept and did not have time for breakfast, your first patient arrives late and the physiotherapist in charge is telling yo' that you cannot have your afternoon off this month. In effect you have been exposed to mounting frustration. Along comes this very patient, he or she may not even be too trying that very morning but here comes your opportunity to let off steam, and you virtually want to "wring her neck". Here your own frustrating agent is triggering off your violent reaction and you turn him into a symbol for all the frustration. Whether you actually let off steam or not is not so important, but that is the way you feel. You are even entitled to it but you must realize that you are projecting your own emotions on the patient-and that if you allow your feelings to get the better of you, you will feel very guilty afterwards. Anxiety is precipitated and the next morning you try to make up for it by giving him all the attention he wants.

You are then truly responsible for creating a situation where the patient manipulates you and not the other way round.

How should one deal with a situation like this? There are many avenues and we all react differently. Some of us will be able to tolerate this magnificently and contain our own frustrations until we go home, but then it pours out and the poor husband or boy-friend suffers. Or we may even work it out on the tennis court by hitting the ball extra hard! That is even a socially acceptable way. If we could try to look at the whole situation objectively from the beginning we would never become so hopelessly entangled in it. If we realize that this demanding patient is merely testing our tolerance and in fact craving for love and recognition, that he is not necessarily directing his aggression against us personally but as a symbol, thereby repeating his lifelong pattern of response. His needs for love and recognition might have been frustrated at one or another time and his only means of getting any attention or recognition, even on 
the negative side and forcing it, is by demanding that attention.

\section{The Difficult Patient}

The best illustration of this negative approach is the child throwing a temper tantrum. We shall never succeed with this patient if we reject him completely. This is what has been happening to him all the time. We can only hope to re-educate him if we show and prove to him that there are more profitable and constructive ways of getting our attention. That is in fact if we give him attention when he really needs it and assure him and explain to him that we shall give it to him if his demands are reasonable. Even more than that, if we show him that we accept him as a person, not necessarily accepting his behaviour.

If we give him our attention the way he demands it, we are merely feeding his neurotic needs and this is where we will make mistakes so easily in the beginning, because it is no longer a therapeutic relationship.

\section{The Group or Teamwork}

It is difficult when one becomes emotionally involved to be able to solve the problem alone. That is where the group should work as a training mechanism in human relations. We are not working alone, we have our fellow workers, the doctors, nurses, etc. with whom we work together and who experience very much the same thing.

I feel personally that this training in human relations is a vital factor which is not being given enough credit in our training programme. We do have lectures in psychology. But it does not help one very much in the handling of a difficult patient to know the theories of Jung, Freud and Adler combined. The young physiotherapist is most often completely unaware and ignorant in that respect and I feel, that if no time can be spared to include this in the training programme, the more experienced of us should make it our task to help them. We don't seem to mind sharing our technical and practical knowledge with them but we forget the human psychological element far too often. Perhaps we ourselves are not truly orientated. It would be so much more profitable if we work it out together and discuss it. If we feel inadequate to deal with a particular problem we should get help from the doctor in charge or the whole team working with the patient.

For a sound therapeutic relationship it is not only important that we alone strive for it but that we help to create a therapeutic climate in our department. By that I mean having a true team spirit in our department and making the patient an active part of the team, the most important part of the team. If we do not realize our interdependence and are only working for our own glory, the enhancement of our ego, unable to accept constructive critisicm we shall find this reflected in the atmosphere of the department. Very often this responsibility rests heavily on the leader of the team but every single member of a unit must be aware of her share and contribution in this responsibility.

\section{The Human Being}

One might still argue about the validity of the points mentioned so far and still ask how does it affect you personally if you have to treat a fibrositis or a fractured femur. Our whole way of thinking is wrong as long as we consider our patients not as human beings but as cases such as frozen shoulders, sprained ankles, etc. We leave out the most vital element. Naturally the depth or intensity of relationship varies. A so-called straightforward, short-termed case, otherwise well adjusted, does not need our attention and consideration as much as a paraplegic patient for instance. Still even this patient needs our acceptance and understanding. With any long-termed case-such as a poliomyelitis patient, a paraplegic patient, a rheumatoid arthritis, etc. our whole treatment and the success of our treatment is based on the soundness of our relationship with the patient. There we are hopelessly failing if we accept our responsibility only as far as his physical rehabilitation is concerned. It is equally important to help the patient emotionally, help him to learn to accept his disabilities and learn to make the most of his abilities or helping him to keep his fighting spirit going - as the case may be.

\section{The Long-term Patient and Rehabilitation}

These patients, however normal and adjusted-are under terrific emotional stress and in their striving for adjustment they need all the encouragement and recognition of their efforts that we can possibly give them. This aspect should not be ignored and every effort made to talk with the patient.

As one of the leading members in the team in rehabilitating handicapped patients it is not only our duty to assist the patient himself with his emotional problems but to reeducate his family as well.

To illustrate this point one sees this so clearly in the example of the over-protective mother with a handicapped child, who means so well in her own mind but who obstructs the child's striving for independence and equilibrium completely and thereby also obstructs what we are aiming at. To quote another example: the situation that arises when one tries to teach a little polio child to walk outside the the department with an audience of other people around and all they can say is: "shame, poor little thing"!

We have an obligation for re-education of the public in. general-indeed a huge task! There is another problem, a problem that we all come across at one stage or another and that is having to accept failure.

\section{The Acceptance of Failure}

I do not like the word "failure" very much. It is difficult to define and may have different meanings for the individual. Generally speaking, failure implies to us that we have not reached a goal that was set and the afterthought that follows right away is who or what is to be blamed. Whom can one blame, if one cannot get a deteriorating patient, such as an amyotrophic lateral sclerosis patient to walk again. Very often we ourselves are to blame because we are not sure in our own mind about what we are trying to achieve. It is indeed not easy, particularly for a physiotherapist who has had little experience with this type of patient to decide how much one is likely to achieve, and it requires careful consideration in order to save disappointment. It may be wiser to put one's goal forward step by step-until one can be really sure about the final goal. I have always found that not being able to achieve the physical improvement that one would like to achieve is a very traumatic experience for everyone of us. It provokes doubts about one's own abilities and can result in a withdrawal, followed by a very real depression or can result in an aggressive, rejecting reaction. One thinks "just too bad" and that again is followed by very uncomfortable guilt feelings and resentment towards the patient or fate in general. What, conflicts!

Before one knows what is happening one becomes so deeply emotionally involved that one cannot possibly help the patient any more. On the other hand once one feels immensely sorry for a patient the relationship with the patient cannot possibly be therapeutic any more either because then one starts identifying one's self or somebody close to one with the patient, consciously or unconsciously:

"There by the Grace of God, go I."

Most of the time it is an unconscious process. We must all learn to accept that there are patients for whom our treatment or medicine as such-has limited value. The danger of accepting failure too readily is just as eminent and results too easily in this attitude of "there is nothing we can do". There is always something that we can do. If it is not for the physical benefit of the patient we can at least give him empathy and help him psychologically. I personally struggled very much with the problem of facing incurable diseases and the feeling of utter helplessness that one experiences. One of our doctors helped me tremendously by telling me about a patient who died of an incurable disease and left the following note for his doctor, in which he said: "I knew you could not help me, but you could at least have said 'good morning' to me".

Sometimes the process of identifying with our patients 
can be very helpful and at times it would be good if we did it a bit more often. It is surprising how much one sees if one happens to become a patient oneself.

Do we always consider, what the patient experiences, how he must feel if we are brisk and abrupt because he might upset our plans?

If we were really good observers we should be able to see without many words, that it is more important for us to put this patient at ease and help him to overcome the anxiety that he experiences in this possibly new situation than to impress him.

The demands on us are manifold, but so are the rewards in our work. Our approach, bearing in mind our definition of understanding and accepting the patients' psychological needs as well as our own and their inter-reaction should never become a rigid one.

\section{Adaptability and the Physiotherapist}

We are dealing with people of all ages. This alone demands a great versatility from us and moreover here in South Africa we are dealing with people with a very varied cultural background. We should accept this as a challenge which makes our work all the more stimulating.

One finds for example that some physiotherapists are very capable in the way that they deal with normal adult patients, but are at a complete loss when they have to treat children or old people or vice versa. Surely this has a significance.

Treating a child can be very demanding on us, particularly, if we are unable to appreciate the child's mental level. We need a lot of tolerance and understanding. We are dependent on their co-operation and goodwill, particularly, if it is going to be a long-term treatment. If we expect the child to conform to treatment in the way that we expect an adult to conform, we have only ourselves to blame if we fail.

We have to be adaptable or we should at least be honest enough to acknowledge our shortcomings and leave this type of work to others. We can for instance not expect a child of pre-school age to be wildly enthusiastic about P.N.F. patterns right from the start, even if one is convinced that P.N.F. is the best form of treatment for this polio child. One has to modify. Whether one does it with marbles or brick houses or stories does not matter as long as one can get the child to take an interested, animated part in the treatment that does at least ensure an 80 per cent co-operation whereas if one would insist on an autocratic approach one could only hope for 50 per cent co-operation and at the same time create a fantastic amount of frustration in the therapist and child.

If the relation between therapist and child is a sound one the child will allow one to build up one's demands gradually. But one should go carefully about it so as not to destroy a trusting relationship that took a long time to develop.

\section{The Psychoneurotic Patient}

So far these thoughts with one exception only dealt with the so-called normal, more or less adjusted patient. What about the psychoneurotic patient? It is an established fact that even in general physiotherapy the percentage of conditions with a psychogenic cause or overlay-is very high. How many really well adjusted patients do we meet in general practice?

It is all very well to say: "it is just psychogenic" thereby putting the blame on to something that we do not want to know about. We only show that we cannot accept or understand it.

To illustrate this point we might only consider a patient with a simple fibrositis. How many of those we are treating are caused by tension alone? We can continue giving them frictions or any other physical treatment until eternity. We shall never cure them.

The subject of the psychoneurotic patient and our approach to him is a vast and complicated one. For our practical working knowledge I would like to distinguish three groups:

1. The purely psychoneurotic patient, e.g., the hypochondriac and the hysterical patient.
2. The psychoneurotic patient who also happens to have an organic condition such as osteo-arthritis or a traumatic condition. These we encounter very frequently.

3. The patient with an organic physical condition with a strong psychogenic element or overlay. I would say that this is the case in at least 50 per cent of our general patients.

We might be able to get away with not paying too much attention to a more psychological approach with general patients, but when dealing with any of tnese three groups, we shall fail miserably if we do not understand the underlying dynamics.

Why do we find psycho-neurosis as such so difficult to accept and why is the stigma that we attach to it still so strong even with professional people? If one goes really deeper into this one finds we deny it because of lack of understanding. These particular patients might present a feature of behaviour that we dislike intensely in ourselves and have therefore repressed and cannot accept. To see it openly and without disguise in others is therefore a painful experience for us. Or it may be, that we associate that particular feature or a particular situation with an unpleasant memory of our childhood experience; to give you an example of the mechanisms that may be involved.

Is it not significant, that some of us are able to tolerate a hysterical patient or an aggressive patient and others cannot stand the sight of them? Or that we take an unrealistic dislike to some people?

Any of these three groups of patients cannot be cured with physiotherapy alone, even with a correct psychological approach by the physiotherapist. We can only make our contribution within the framework of the team which must include related professions: medical, nursing, etc.

If we think, that we can do this alone by telling the patient to pull himself together or the classical: "don't worry" or rationalizing, we only prove our inadequacy to tackle the real problem.

Even in general practice we might help the doctor already by pointing out our objective observations as we see the patient for so much longer periods. Even if we said that we are unable to cope with it and that our treatment is of no benefit. It would be more honest than to accept being the dumping ground for a large number of patients the doctors want to get rid of, at least temporarily.

\section{Hysterical Paralysis}

It might be worthwhile to discuss one type of patient who is a particular problem, that is the patient with a hysterical paralysis. We need to understand that this patient is just as sick or even more so than the patient with an organic lesion. The symptoms that he presents are nothing but a defence mechanism that he has built up as a disguise for the real problem. It is not just as simple as that he does not want to walk any more. $\mathrm{He}$ is in fact crying out for help by demonstrating his symptoms and using an escape mechanism. If we are only concerned with bullying his defence mechanism away by means of high faradic current or other forceful treatment, we are only breaking down his last reserve and leaving him completely at sea. We may, that way even contribute to his complete breakdown. There we can only be successful if we build up a strong nonjudgmental relationship and work in close co-operation with the psychiatrist. That means, that we accept a supporting role and proceed with our attempts in tune with the progress that the patient makes in his psychotherapy. As he gains insight and can accept and tackle his real problem and does not need his defence mechanism any more we are ready to take over and prepare him for it, also physically. In the beginning our main task lies in building up a strong supporting relationship and observing as well as looking after his physical symptoms.

\section{Conclusion}

My final plea is that everyone of us should aim at not (Continued on Page 9) 


\section{GENERAL}

\section{WORLD CONFEDERATION FOR PHYSICAL THERAPY}

The Training of Physical Therapists is published in English, French and now in Spanish. This document has been found very useful by many physical therapists, doctors and international bodies setting up physical therapy services.

Any members who would like to have a copy may obtain one from the W.C.P.T., Tavistock House (South), Tavistock Square, London, W.C.l, England.

\section{Summary of Annual Report for 1961}

1961 saw change and progress in the affairs of the World Confederation for Physical Therapy. By 1961 the W.C.P.T. had reached a stage in its development which necessitated the appointment of its own secretariat with Miss M. J. Neilson, M.B.E., who for seventeen years had been secretary of the Chartered Society of Physiotherapy, as the first Secretary General. New offices have been acquired in Eastbury House, Albert Embankment, London, S.E.1, and all physical therapists visiting London will be welcomed there.

The scope and volume of the Confederation's work increased rapidly in the year. Advice was given on the formation and activities of professional associations of physical therapists and on the planning and equipping of physical therapy departments and training schools in various parts of the world.

The Fédération Suisse des Physiothérapeutes was admitted for membership subject to confirmation at the General Meeting 1963.

In the early months of 1961 physical therapists were recruited by the World Confederation, on behalf of the League of Red Cross Societies, to treat Moroccan patients paralysed as a result of using adulterated cooking oil. In conjunction with the Save the Children Fund of Great Britain, the W.C.P.T. found a physical therapist to work in the Children's Pavilion of the Hospital in Fez.

Several physical therapists were recruited to the Aguash Rehabilitation Centre in Cairo to join the team there, consisting of fourteen physical therapists from Denmark, France, Great Britain, Norway, Western Germany and Yugoslavia. A physical therapist from Great Britain (Miss Lois Dyer, one-time of the General Hospital, Johannesburg and former editor of Physiotherapy Journal of S.A.S.P.) who had lately returned from Morocco, was appointed jointly by the Egyptian Veterans and War Victims' Association and the World Veterans' Federation as leader of the team.

In July 1962 at the European International Conference on Rehabilitation to be held in King's College, Cambridge, the W.C.P.T. will be responsible for a session on Physical Therapy. A Swedish physical therapist will read a paper on "The Rehabilitation of Forestry Workers with Back Injuries in Sweden" and a British physical therapist will speak on "The Physical Therapist's Role in the Rehabilitation of Patients of all Ages".

The Executive Committee, in submitting this report, records its gratitude both to the Member Organizations and to their individual members who have supported the organization in many ways, such as working on documents and pamphlets prepared by the committee, by representing the Confederation at international meetings in their own countries and reporting thereon, and last but not least, by providing the financial resources which make possible the work of the World Confederation for Physical Therapy.

This report, in full, was submitted by Rudie Agersnap, President on behalf of the Executive Committee, W.C.P.T.

\section{FOURTH CONGRESS}

\section{Copenhagen, 17th to 22nd June, 1963}

The S.A.S.P. Central Executive Committee is investigating the possibilities of arranging reduced Air Fares to Copenhagen for the Congress.

Interested persons are asked to contact the General Secretary, P.O. Box 11151 , Johannesburg.
JOHANNESBURG COUNCIL FOR THE CARE OF THE AGED

Mr. A. Rothberg has been elected to represent the S.A.S.P. on the above Council.

\section{COMPULSORY REGISTRATION}

The Society's publicity campaign has swung into top gear with the Central and Branch Action's Committee working at high pressure.

Two News Letters have been sent to members of the public and encouraging replies have been received from influential people including Members of Parliament and doctors.

\section{Letter to the Editor}

\section{Dear Madam,}

$$
\text { RE-FIBROSITIS }
$$

While there is at the moment great interest in the attainment of compulsory registration of physiotherapists for the protection of the public, I would like to express an opinion on a subject closely connected with this.

Recently I read in the parliamentary report of a S.A. newspaper that one honourable member felt that many M.P.'s would not have been cured of their fibrositis had jt not been for Chiropractors. I do not doubt the truth of this statement, as in my opinion this is a condition for which the medical and physiotherapy professions in South Africa have yet failed to find a cure. In fact, physiotherapists are often required to treat cases with referred pain in the cervical or lumbar region ("fibrositis" or "lumbago") without a diagnosis, i.e. without an indication of the cause of this pain. The result is that the symptomatic treatment so often administered (heat, massage, etc.), does little but keep the patient under the illusion that he or she is receiving treatment, while nature is effecting the cure.

In my experience, many of these patients can be successfully treated by spinal manipulation and traction, properly applied according to the pathology indicated by an accurate diagnosis, and the signs presented by each case.

If physiotherapists in South Africa were trained to carry out these techniques under the guidance of doctors, the honourable M.P.'s could be cured of their "fibrositis" under proper medical care. It is time the S.A.S.P. seriously considered asking an expert in these techniques to visit this country in order to initiate the training.

\section{Yours sincerely,} Brun. Winter, M.C.S.P.

\section{(Continued from page 5)}

just being a "physio", but also a "therapist", in fact try to make it a happy combination of "physiotherapist".

I think in our profession the danger of becoming and training mere technicians is even greater than in many other related professions, I would personally even go further and say that a really good therapist will also aim at giving the patient the treatment that has a high professional standard; but that may be debatable.

For the end results it might not matter whether we arrive at a happy solution from one end or the other as long as we give consideration to both.

Any one who has seriously and sincerely tried to apply a more psychological approach to patients will bear me out that this can make our work so much more rewarding and richer.

I wish to place on record my appreciation to Dr. $\mathrm{H}$. Moross, Medical Superintendent, Tara Hospital for his help and permission in the writing of this contribution.

\section{BiBLIOGRAPHY}

GiLlıs, L. S., M.D., D.P.M., 1962. Title: Human Behaviour in Illness, Psychology and Interpersonal Relationship. Publisher: Faber and Faber, London. 